\title{
PTEN Mediates the Antioxidant Effect of Resveratrol at Nutritionally Relevant Concentrations
}

\author{
Marta Inglés, ${ }^{1}$ Juan Gambini, ${ }^{2}$ M. Graça Miguel, ${ }^{3}$ Vicent Bonet-Costa, ${ }^{2}$ \\ Kheira M. Abdelaziz, ${ }^{2}$ Marya El Alami, ${ }^{2}$ Jose Viña, $^{2}$ and Consuelo Borrás ${ }^{2}$ \\ ${ }^{1}$ Department of Physiotherapy, Faculty of Physiotherapy, University of Valencia, Gascó Oliag Street 5, 46010 Valencia, Spain \\ ${ }^{2}$ Department of Physiology, Faculty of Medicine, University of Valencia, Blasco Ibañez Avenue 15, 46010 Valencia, Spain \\ ${ }^{3}$ Centro Biotecnologia Vegetal, Faculdade de Ciências e Tecnologia, Instituto de Biotecnologia e Bioengenharia, \\ Universida de do Algarve, Campus de Gambelas, Edifício 8, 8005-139 Faro, Portugal
}

Correspondence should be addressed to Consuelo Borrás; consuelo.borras@uv.es

Received 2 February 2014; Revised 12 March 2014; Accepted 13 March 2014; Published 10 April 2014

Academic Editor: Efstathios S. Gonos

Copyright (C) 2014 Marta Inglés et al. This is an open access article distributed under the Creative Commons Attribution License, which permits unrestricted use, distribution, and reproduction in any medium, provided the original work is properly cited.

\begin{abstract}
Introduction. Antioxidant properties of resveratrol have been intensively studied for the last years, both in vivo and in vitro. Its bioavailability after an oral dose is very low and therefore it is very important to make sure that plasma concentrations of free resveratrol are sufficient enough to be active as antioxidant. Aims. In the present study, using nutritionally relevant concentrations of resveratrol, we aim to confirm its antioxidant capacity on reducing peroxide levels and look for the molecular pathway involved in this antioxidant effect. Methods. We used mammary gland tumor cells (MCF-7), which were pretreated with different concentrations of resveratrol for $48 \mathrm{~h}$, and/or a PTEN inhibitor (bpV: bipy). Hydrogen peroxide levels were determined by fluorimetry, PTEN levels and Akt phosphorylation by Western Blotting, and mRNA expression of antioxidant genes by real-time reverse transcriptase-polymerase chain reaction (RT-PCR). Results. Resveratrol treatment for $48 \mathrm{~h}$ lowered peroxide levels in MCF7, even at low nutritional concentrations ( $1 \mathrm{nM})$. This effect was mediated by the activation of PTEN/Akt pathway, which resulted in an upregulation of catalase and MnSOD mRNA levels. Conclusion. Resveratrol acts as an antioxidant at nutritionally relevant concentrations by inducing the expression of antioxidant enzymes, through a mechanism involving PTEN/Akt signaling pathway.
\end{abstract}

\section{Introduction}

In the last two decades, life expectancy at birth has increased by $5-10$ years [1]. As a consequence, the population is growing older and therefore there is increasing interest in how to face age-related problems. Oxidative damage to biomolecules caused by reactive oxygen species (ROS) plays an important role in the aging process, as stated in the free radical theory of aging [2]. This occurs when an imbalance between the production of free radicals and the ability of the natural antioxidant defenses to scavenge them exists. We have previously suggested the possibility that the intake of nonvitamin antioxidants such as nutrients or natural compounds may be effective in increasing antioxidant defenses, by upregulating the activity of antioxidant enzymes, which are normally present in cells [3]. One of these plausible antioxidants is resveratrol (trans-3,5, $4^{\prime}$-trihydroxystilbene), a natural polyphenol found in many plants and fruits, such as blueberries, blackberries, peanuts, and grapes, and specially in red wine, the main source in the human diet [4]. Resveratrol properties as an antioxidant have been intensively studied for the last years [5-10], both in vivo and in vitro, but the mechanism involved remains unclear. Moreover, its bioavailability after an oral dose is very low. In fact, plasma concentrations of free transresveratrol after ingestion of $600 \mathrm{~mL}$ of red wine [11] or an oral dose of $25 \mathrm{mg}[12,13]$ are extremely low, of the order of nanomolar or low micromolar. Therefore, it is very important to make sure that those nutritionally relevant low plasma concentrations of free resveratrol are sufficient enough to be active as an antioxidant $[13,14]$.

One of the antioxidant effects attributed to resveratrol is the ability to protect cells against $\mathrm{H}_{2} \mathrm{O}_{2}$-induced oxidative 


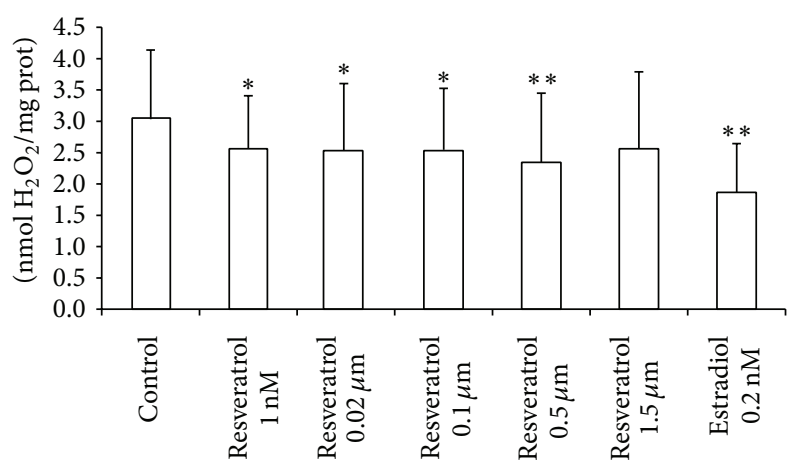

FIGURE 1: Resveratrol diminishes hydrogen peroxide levels in MCF7 cells. Peroxide levels were determined by fluorimetry using homovanillic acid (see Section 3). Cells were treated with resveratrol or with estradiol for $48 \mathrm{~h}$. Data are expressed as means + SD for 15 different experiments; ${ }^{*} P<0.05 ;{ }^{* *} P<0.01$ versus control.

stress $[15,16]$. Furthermore, resveratrol is able to increase the phosphatase and tensin homolog PTEN [17, 18], a wellknown tumor suppressor that antagonizes the activity of phosphatidylinositol 3-kinase type I (PI3K), thus leading to decreased phosphorylated-Akt (P-Akt) levels [19]. Interestingly, it has been recently reported that PTEN is able to increase energy expenditure and improve organismal survival independently of its effect on cancer, thus suggesting that PTEN might have multiple protective functions [20].

We have previously reported that oestradiol and genistein are able to decrease hydrogen peroxide levels in MCF-7 cells [21, 22]. Using the same cell line, we report that nutritionally relevant concentrations of resveratrol are able to decrease hydrogen peroxide levels not because of its phenolic structure, but because of the fact that it induces the expression of antioxidant genes, such as catalase (Cat) and manganese superoxide dismutase (MnSOD), through a mechanism that involves phosphatase and tensin homolog (PTEN) and protein kinase-B (PKB or Akt) signaling pathway. This finding may be useful to support the idea that, despite having low bioavailability, it is possible to consider resveratrol as an important nonvitamin antioxidant and to provide new insights into the mechanism involved in it.

\section{Results}

2.1. Nutritional Concentrations of Resveratrol Decrease Hydrogen Peroxide Levels in MCF-7 Cells. Figure 1 shows that resveratrol treatment for $48 \mathrm{~h}$ lowers hydrogen peroxide levels, except at the highest dose $(1.5 \mu \mathrm{M})$. These concentrations are similar to those of free trans-resveratrol found in plasma after ingestion of $600 \mathrm{~mL}$ of red wine [11] or an oral dose of $25 \mathrm{mg}$ [12, 13]. Therefore, we find antioxidant effects of resveratrol at nutritionally relevant concentrations.

\subsection{Resveratrol Increases PTEN Protein Levels in MCF-7 Cells.} In order to find out the mechanism by which resveratrol acts as an antioxidant, we tested if PTEN signaling pathway could be involved in its antioxidant effect. We found that resveratrol

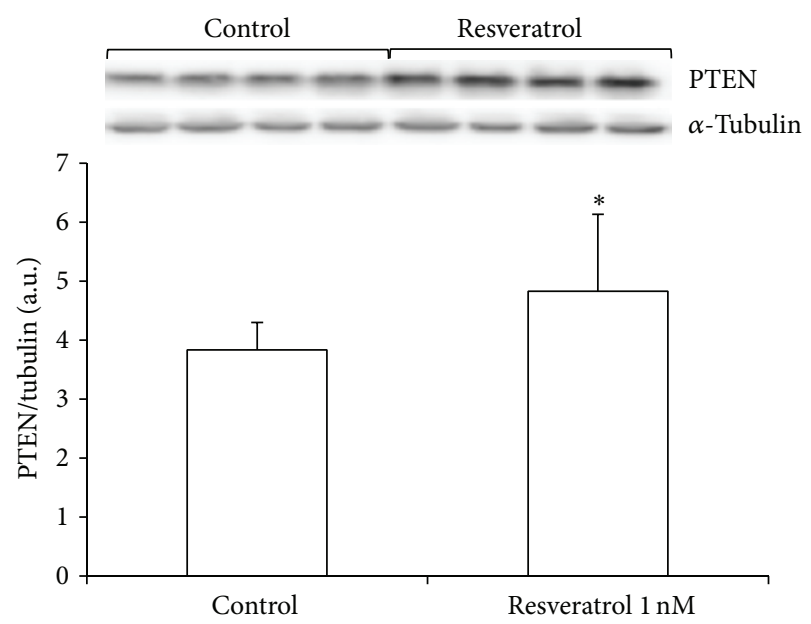

FIgURE 2: Resveratrol activates the PTEN signaling pathway. Levels of PTEN were measured in cells treated for $48 \mathrm{~h}$ with resveratrol $(1 \mathrm{nM})$. Data are expressed as means + SD for 4 different experiments; ${ }^{*} P<0.05$ versus control.

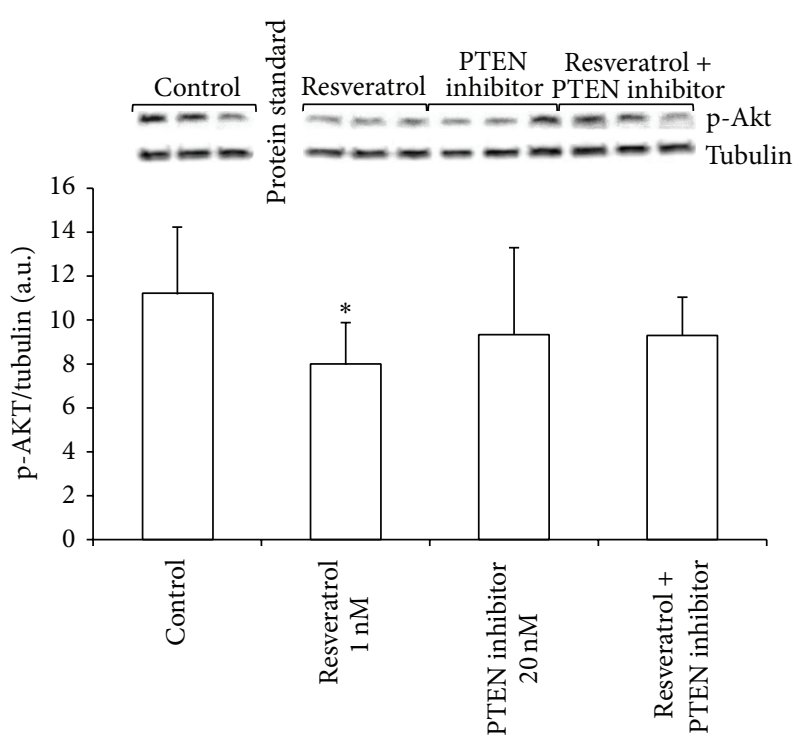

FIGURE 3: Resveratrol inactivates the Akt signaling pathway through PTEN activation in MCF-7 cells. Phospho-Akt levels were measured by Western blotting, after $48 \mathrm{~h}$ incubation with resveratrol $(1 \mathrm{nM})$ alone, potassium bisperoxo (bipyridine) oxovanadate (V) as a PTEN inhibitor alone $(20 \mathrm{nM})$, or both together. Histograms represent densitometric measurement of specific bands of phospho-Akt content using tubulin levels as housekeeping control. Data are expressed as means + SD for 4 independent experiments; ${ }^{*} P<0.05$ versus control.

treatment for $48 \mathrm{~h}$ increased PTEN protein levels in MCF-7 (Figure 2).

2.3. Resveratrol Decreases Akt Phosphorylation via PTEN Activation in MCF-7 Cells. Figure 3 shows that incubation of MCF-7 cells with physiological concentrations of resveratrol $(1 \mathrm{nM})$ for $48 \mathrm{~h}$ reduces the phosphorylation of Akt. This effect can be seen within 5 minutes of incubation and 


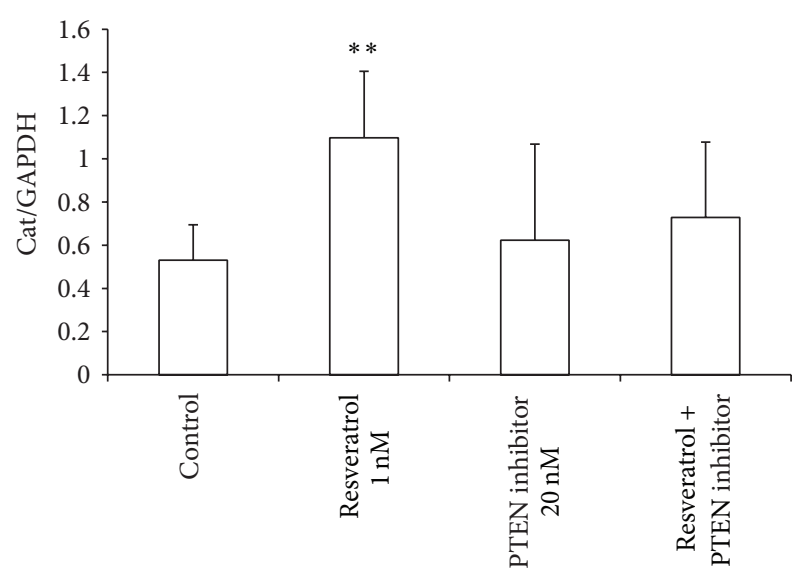

(a)

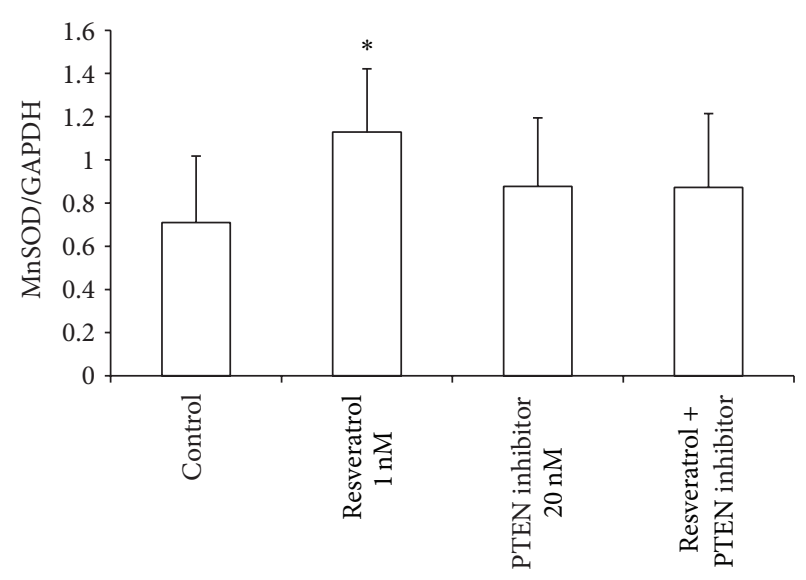

(b)

Figure 4: Resveratrol upregulates the expression of catalase (a) and MnSOD (b) in MCF-7 cells. Resveratrol (1 nM) increased mRNA levels of catalase and Mn-superoxide dismutase $\left({ }^{*} \mathrm{P}<0.05\right.$; ${ }^{* *} \mathrm{P}<0.01$ versus control), and these effects were prevented when coincubating with the PTEN inhibitor $(20 \mathrm{nM})$. Data are expressed as means + SD for 3 different experiments.

reaches the maximum within $48 \mathrm{~h}$. Coincubation with an inhibitor of PTEN activity (potassium bisperoxo (bipyridine) oxovanadate $(\mathrm{V})$ ) at a dose of $20 \mathrm{nM}$ reverts this effect. Therefore, the decrease in Akt phosphorylation by resveratrol is mediated by PTEN activation.

2.4. Resveratrol Upregulates Endogenous Antioxidant Genes via PTEN Signaling Pathway. Nutritional concentrations of resveratrol upregulate the expression of catalase (Figure 4(a)) and MnSOD (Figure 4(b)) after $48 \mathrm{~h}$ of incubation. However, this upregulation is prevented when cells are coincubated with a PTEN inhibitor, suggesting the implication of PTEN in resveratrol-mediated activation of endogenous antioxidant gene expression.

2.5. PTEN Mediates the Antioxidant Effect of Resveratrol in MCF-7 Cells. As stated before, $1 \mathrm{nM}$ resveratrol pretreatment led to a reduction in intracellular hydrogen peroxide levels. However, Figure 5 shows how coincubation with a PTEN inhibitor $(20 \mathrm{nM})$ reverts this antioxidant effect.

\section{Materials and Methods}

3.1. Cell Culture. Human mammary gland tumor cells (MCF7) were cultured in Iscove's modified Dulbecco's medium (IMDM) without phenol red, supplemented with $10 \%(\mathrm{v} / \mathrm{v})$ heat-inactivated fetal bovine serum. Cells were plated in 25 or $75 \mathrm{~cm}^{2}$ culture flasks and maintained at $37^{\circ} \mathrm{C}$ with $5 \% \mathrm{CO}_{2}$ in air. All the experiments were performed once cells reached confluence.

3.2. Treatments. Based on previous experiments of our laboratory $[21,22]$ and on the literature $[17,18]$, cells were treated for $48 \mathrm{~h}$ with either DMSO (for the control group), resveratrol (at concentrations ranging from $1 \mathrm{nM}$ to $1.5 \mu \mathrm{M}$ ), or resveratrol together with $20 \mathrm{nM}$ bisperoxo (bipyridine) oxovanadate $(\mathrm{V})$ as PTEN inhibitor [23]. 0.2 nM estradiol was

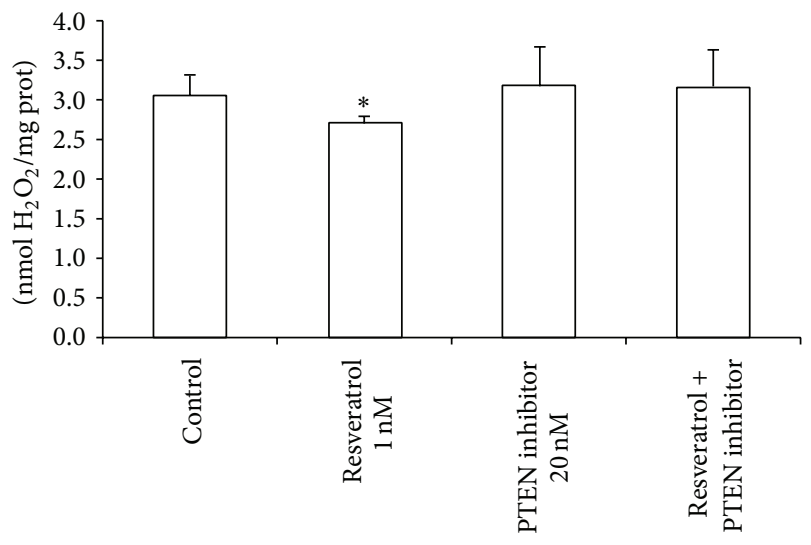

FIGURE 5: Resveratrol diminishes peroxide levels in MCF-7 cells, and this effect is mediated by the PTEN/Akt signaling pathway. MCF-7 cells were treated with resveratrol $(1 \mathrm{nM})$ alone, potassium bisperoxo (bipyridine) oxovanadate (V) as a PTEN inhibitor alone $(20 \mathrm{nM})$, or both together. Data are expressed as means + SD for 4-8 different experiments; ${ }^{*} P<0.05$ versus control.

used as a positive control when measuring hydrogen peroxide levels [21].

3.3. Determination of Peroxide Levels in MCF-7 Cells. Intracellular levels of hydrogen peroxide were determined by fluorimetry using a modification of the method described by Barja [24].

Briefly, cells were washed twice with PBS and then incubated at $37^{\circ} \mathrm{C}$ with a PBS solution containing $0.1 \mathrm{mM}$ homovanillic acid and $6 \mathrm{U} / \mathrm{mL}$ horseradish peroxidase. The incubation was stopped at $5 \mathrm{~min}$ with $1 \mathrm{~mL}$ of cold $2 \mathrm{M}$ glycine buffer containing $50 \mathrm{mM}$ EDTA and $2.2 \mathrm{M} \mathrm{NaOH}$. The fluorescence of supernatants was measured using $312 \mathrm{~nm}$ as an excitation wavelength and $420 \mathrm{~nm}$ as an emission wavelength. 
The levels of peroxides were calculated using a $\mathrm{H}_{2} \mathrm{O}_{2}$ standard curve and results were expressed per milligram of protein.

3.4. Immunoblot Analysis of Akt Phosphorylation and PTEN Protein Expression Levels. After $48 \mathrm{~h}$ of pretreatment with resveratrol, cells were washed twice with cold PBS and lysed in cold lysis buffer $\left(62.5 \mathrm{mM}\right.$ Tris- $\mathrm{HCl}\left(\mathrm{pH} 6.8\right.$ at $\left.25^{\circ} \mathrm{C}\right)$, $2 \% \mathrm{w} / \mathrm{v}$ SDS, $10 \% \mathrm{v} / \mathrm{v}$ glycerol), which was supplemented with a protease inhibition cocktail $(10 \mu \mathrm{L}$ per $1 \mathrm{~mL}$ of lysis buffer) and sodium orthovanadate $200 \mathrm{mM}(10 \mu \mathrm{L}$ per $1 \mathrm{~mL}$ of lysis buffer) to inactivate proteases and phosphatases. Immediately after harvesting, aliquots of whole cell lysates (40 $\mu \mathrm{g}$, based on previous experiments [21, 22]) were boiled for $10 \mathrm{~min}$, electrophoresed on SDS $10 \%$ polyacrylamide gels, and electroblotted (Bio-Rad) onto a PVDF membrane (Bio$\mathrm{Rad})$. Membranes were blocked at room temperature for 1 hour with $0.05 \mathrm{~g} / \mathrm{mL}$ nonfat milk or BSA $0.05 \mathrm{~g} / \mathrm{mL}$ in TBS$0.1 \%$ Tween 20 (TBS-T) according to the antibody. Afterwards, membranes were incubated with primary antibodies against phospho-Akt Ser 473, PTEN (1:1000, Cell Signaling Technologies, Boston, MA, USA), or $\alpha$-tubulin as loading control (1:1000, Santa Cruz BioTech USA), overnight at $4^{\circ} \mathrm{C}$. Blots were then washed again three times for $10 \mathrm{~min}$ at room temperature and then incubated for $1 \mathrm{~h}$ with a secondary horseradish peroxidase (HRP) linked anti-rabbit IgG antibody (1:2000) (Cell Signaling, Boston, MA, USA). After washing three times again, membranes were developed by using the ECL Prime Western Blotting Detection reagent as specified by the manufacturer (Amersham Pharmacia, USA). Autoradiographic bands were assessed using a Fujifilm scanning densitometer (Fujifilm LAS-1000 plus). The densitometric analysis was performed using Image J 1.34s software. For comparison between blots, one aliquot of the same sample was loaded as a standard in each gel to allow data normalization.

3.5. mRNA Gene Expression. Catalase (Cat) and manganese superoxide dismutase (MnSOD) mRNA expression was determined by real-time PCR with glyceraldehyde-3P-dehydrogenase (GAPDH) as the endogenous control, according to previously published results $[21,22]$.

For this purpose, total RNA was isolated from cultures by extraction with TRIzol Reagent (Invitrogen), according to the manufacturer's instructions. RNA was quantified by measuring the absorbance at $260 \mathrm{~nm}$. The purity of the RNA preparations was assessed by the $260 / 280$ ratio.

cDNA was synthesized from $1 \mu \mathrm{g}$ total RNA using a reverse transcriptase (RT) system kit of Applied Biosystems (High-Capacity cDNA Reverse Transcription Kits). The reaction was incubated as recommended by the manufacturer, for $10 \mathrm{~min}$ at $25^{\circ} \mathrm{C}$, followed by $120 \mathrm{~min}$ at $37^{\circ} \mathrm{C}$, and then for $5 \mathrm{~min}$ at $85^{\circ} \mathrm{C}$, and finally cooled to $4^{\circ} \mathrm{C}$ to collect the cDNA and then stored at $-20^{\circ} \mathrm{C}$ prior to the real-time PCR assay.

The quantitative PCR was performed using the detection system 7900HT Fast Real-Time PCR System (Applied Biosystems) with Maxima SYBR Green/ROX qPCR Master Mix (2X) (Fermentas). Target and control were run in separate wells.
Specific primers employed, sense and antisense for each gene, respectively, were MnSOD, 5'-CGT GCT CCC ACA CAT CAA TC- $3^{\prime}$ and $5^{\prime}$-TGA ACG TCA CCG AGG AGA AG-3'; Catalase, $5^{\prime}$-ACG TTG GAT GGA GAA GTG CGG AGA TTC AAC- $3^{\prime}$ and $5^{\prime}$-ACG TTG GAT GTT CAC ATA GAA TGC CCG CAC- $3^{\prime}$; and GAPDH, $5^{\prime}-\mathrm{CCT}$ GGA GAA ACC TGC CAA GTA TG- $3^{\prime}$ and $5^{\prime}$-GGT CCT CAG TGT AGC CCA AGA TG-3'. Target cDNAs were amplified in separated tubes using the following procedure: $10 \mathrm{~min}$ at $95^{\circ} \mathrm{C}$ and then 40 cycles of denaturation at $95^{\circ} \mathrm{C}$ for $15 \mathrm{~s}$ and annealing and extension at $62^{\circ} \mathrm{C}$ for $1 \mathrm{~min}$ per cycle.

The standard curve method was used to evaluate the relative expression levels of catalase and MnSOD in resveratrol pretreated MCF-7 cells. Briefly, the threshold cycle (Ct) was determined and converted to a relative amount through the use of a standard curve prepared from dilutions of cDNA mix of all samples. The logarithmic formula used to transform $\mathrm{Ct}$ values was

$$
\operatorname{Exp}=\frac{(\mathrm{Ct}, \text { sample }- \text { Intercept })}{\text { Slope }}
$$

3.6. Statistical Analysis. Quantitative variables are expressed as means and standard deviation of different experiments. Once the normality of the variables was tested by Kolmogorov-Smirnov test, the statistical analysis was performed using the one-way analysis of variance (ANOVA) test to check any possible statistically significant difference between groups and the adequate post hoc tests. The level of significance was chosen at $P<0.01$ or $P<0.05$. All analyses were performed using SPSS statistical software version 19.0.

\section{Discussion}

Antioxidant supplementation is a common medical practice among the elderly [25]. We report here that the antioxidant effect of low nanomolar concentrations of resveratrol is mediated via the upregulation of antioxidant gene expression, involving activation of PTEN/Akt signaling pathway.

Numerous studies have reported the beneficial antioxidant properties of resveratrol. For example, in human blood platelets treated with peroxynitrite, resveratrol inhibited protein carbonylation and nitration, as well as lipid peroxidation [6]. Resveratrol has also been shown to protect primary hepatocytes in culture against oxidative stress damage by increasing the activities of catalase, superoxide dismutase, glutathione peroxidase, NADPH quinine oxidoreductase, and glutathione-S-transferase [7]. In addition, resveratrol was able to diminish oxidative stress by increasing gastrocnemius catalase activity, MnSOD activity, and MnSOD protein content in young and old rats submitted to a 14-day muscle disuse by hindlimb suspension [9].

In our cellular model, resveratrol also acts as an antioxidant by increasing MnSOD and Cat mRNA levels, which in turn decreases $\mathrm{H}_{2} \mathrm{O}_{2}$ levels. This $\mathrm{H}_{2} \mathrm{O}_{2}$ decrease is in agreement with studies reporting the ability of resveratrol to protect $\mathrm{PC} 12$ cells against $\mathrm{H}_{2} \mathrm{O}_{2}$-induced cytotoxicity $[15,16]$, suggesting the potential capacity of resveratrol to prevent oxidative stress-induced cell death. In this regard, we checked 
the potential antiapoptotic effect of $1 \mathrm{nM}$ resveratrol on MCF7 cells by measuring BCL-XL levels by Western Blotting. However, we did not find any difference in BCL-XL levels between control and resveratrol group (data not shown), suggesting that the antioxidant effect of such a low dose of resveratrol does not affect apoptosis.

In any case, the mechanism by which resveratrol can exert its antioxidant effect has not been fully elucidated. Resveratrol is able to act as a phytoestrogen and mimic estrogen biological effects [26, 27]. However, it has also been shown to act as an antagonist [28]. In fact, our first experiments aimed to check if resveratrol was able to behave as estradiol in our model system, thus binding to estrogen receptors. However, we could not inhibit resveratrol antioxidant effect when coincubating cells with resveratrol and tamoxifen (an inhibitor of estrogen receptors) (data not shown). Furthermore, resveratrol did not activate MAPK and NF $\kappa$ B signalling pathways, thus suggesting that the pathway involved in the expression of antioxidant genes is not mediated by estrogen receptors or MAPK and $\mathrm{NF} \kappa \mathrm{B}$ signalling pathways. Interestingly, these results suggest that resveratrol antioxidant effects may not change between men and women.

Here we show that PTEN, an antagonist to the PI3K/Akt pathway, is involved in resveratrol antioxidant effects. Resveratrol increases PTEN and decreases phospho-Akt levels. In this regard, Waite et al. observed that preincubation with resveratrol or other phytoestrogens for $48 \mathrm{~h}$ had been able to increase PTEN levels and decrease phospho-AKT levels in MCF-7, at concentrations ranging from $0.1 \mathrm{nM}$ to $1 \mu \mathrm{M}$ [17]. Wang et al. also found an increase in PTEN levels when incubating a prostate cancer cell line with $10 \mu \mathrm{M}$ resveratrol for $24 \mathrm{~h}$ [18]. Interestingly, PTEN has been recently shown to increase the activity of antioxidant enzymes, such as glutathione peroxidase (GPx), Cat, and MnSOD in a lung cancer cell line [29]. This led us to hypothesize and finally demonstrate that PTEN/Akt pathway was involved in resveratrol antioxidant effect.

As stated before, resveratrol bioavailability is very low and its absorption is highly variable, depending on the way it is consumed and the kind of food ingested $[12,13]$. Two of the first human studies on the absorption and bioavailability of resveratrol used a single oral dose treatment of $25 \mathrm{mg}[12,13]$. Despite the use of high sensitivity methods and a specific molecular analysis, the presence of nonmetabolized resveratrol in circulating plasma was difficult to detect. Approximate calculations showed maximal concentrations of $<10 \mathrm{ng} / \mathrm{mL}$ ( $\approx 40 \mathrm{nM}$ ), $0.5-2$ hours after the oral dose. Estimates of the plasma concentrations of resveratrol plus total metabolites were considerably higher, around $400-500 \mathrm{ng} / \mathrm{mL}(\approx 2 \mu \mathrm{M})$, indicating a very low oral bioavailability of free resveratrol, but significant one of its metabolites. Vitaglione et al. also studied the bioavailability of resveratrol after red wine consumption and found low micromolar $(1-6 \mu \mathrm{M})$ or nanomolar concentrations of free trans-resveratrol in plasma [11]. Thus, we chose for our experiment the lowest concentration $(1 \mathrm{nM})$ that was able to diminish hydrogen peroxide levels (see Figure 1). This is indeed within the range of nutritionally relevant concentrations found in plasma after moderate wine

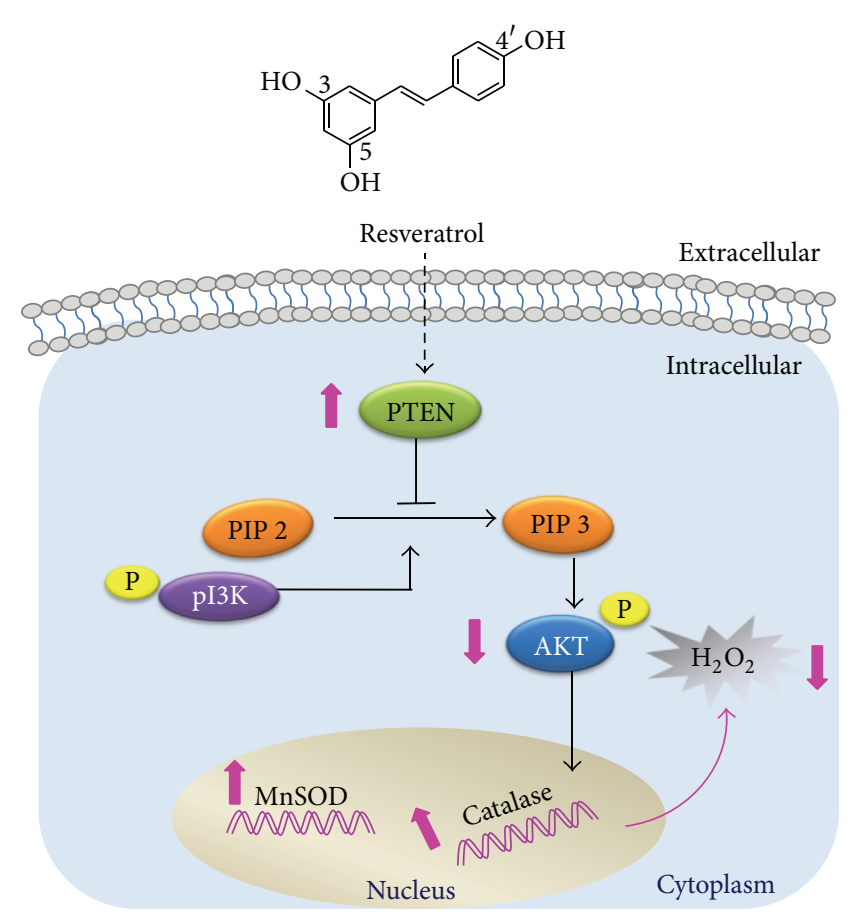

Figure 6: Proposed mechanism for resveratrol to upregulate antioxidant gene expression.

intake. Consuming normal amounts of resveratrol-rich nutrients, such as grapes, peanuts, blueberries, blackberries, and red wine [30], may result in plasma concentrations of free resveratrol that, as we show here, increase the expression of antioxidant genes and thus may delay the onset of oxidative stress-related conditions. Therefore, our results may have practical importance.

\section{Conclusions}

The major conclusion of the current study is that nutritionally relevant concentrations of resveratrol can decrease oxidative stress within the cell by upregulating antioxidant genes. As illustrated in Figure 6, resveratrol increases PTEN levels, which in turn inhibits phosphoinositide 3-kinase (PI3K) function, leading to a decrease in phospho-Akt levels and, finally, to upregulation of antioxidant genes (Cat and MnSOD). As a consequence, lower levels of hydrogen peroxide can be observed within the cell.

\section{Conflict of Interests}

All authors have indicated that they have no financial/ commercial conflict of interests.

\section{Acknowledgments}

This work was supported by grants SAF2010-19498 from the Spanish Ministry of Education and Science (MEC); ISCIII2006-RED13-027 and ISCIII2012-RED-43-029 from 
the Red Temática de Investigación Cooperativa en Envejecimiento y Fragilidad (RETICEF); PROMETEO2010/074 from "Conselleria d'Educació, Cultura i Esport de la Generalitat Valenciana"; 35NEURO Gent x Gent from "Fundacio Gent Per Gent de la Comunitat Valenciana"; and RS2012-609 Intramural Grant from INCLIVA and EU Funded CM1001 and FRAILOMIC-HEALTH.2012.2.1.1-2. This study has been cofinanced by FEDER funds from the European Union.

\section{References}

[1] World Health Statistics, World Health Organization (WHO), Geneva, Switzerland, 2013.

[2] D. Harman, "Aging: a theory based on free radical and radiation chemistry," Journal of Gerontology, vol. 11, no. 3, pp. 298-300, 1956.

[3] J. Viña, M.-C. Gomez-Cabrera, and C. Borras, "Fostering antioxidant defences: up-regulation of antioxidant genes or antioxidant supplementation?" British Journal of Nutrition, vol. 98, supplement 1, pp. S36-S40, 2007.

[4] G. J. Soleas, E. P. Diamandis, and D. M. Goldberg, "Resveratrol: a molecule whose time has come? And gone?" Clinical Biochemistry, vol. 30, no. 2, pp. 91-113, 1997.

[5] G. A. Losa, "Resveratrol modulates apoptosis and oxidation in human blood mononuclear cells," European Journal of Clinical Investigation, vol. 33, no. 9, pp. 818-823, 2003.

[6] B. Olas, B. Wachowicz, P. Nowak et al., "Comparative studies of the antioxidant effects of a naturally occurring resveratrol analogue-trans-3,3',5,5'-tetrahydroxy-4'-methoxystilbene and resveratrol-against oxidation and nitration of biomolecules in blood platelets," Cell Biology and Toxicology, vol. 24, no. 4, pp. 331-340, 2008.

[7] J. A. Rubiolo, G. Mithieux, and F. V. Vega, "Resveratrol protects primary rat hepatocytes against oxidative stress damage: activation of the Nrf2 transcription factor and augmented activities of antioxidant enzymes," European Journal of Pharmacology, vol. 591, no. 1-3, pp. 66-72, 2008.

[8] Y.-B. Yang and Y.-J. Piao, "Effects of resveratrol on secondary damages after acute spinal cord injury in rats," Acta Pharmacologica Sinica, vol. 24, no. 7, pp. 703-710, 2003.

[9] J. R. Jackson, M. J. Ryan, Y. Hao, and S. E. Alway, "Mediation of endogenous antioxidant enzymes and apoptotic signaling by resveratrol following muscle disuse in the gastrocnemius muscles of young and old rats," American Journal of PhysiologyRegulatory Integrative and Comparative Physiology, vol. 299, no. 6, pp. R1572-R1581, 2010.

[10] G. S. Liu, Z.-S. Zhang, B. Yang, and W. He, "Resveratrol attenuates oxidative damage and ameliorates cognitive impairment in the brain of senescence-accelerated mice," Life Sciences, vol. 91, no. 17-18, pp. 872-877, 2012.

[11] P. Vitaglione, S. Sforza, G. Galaverna et al., "Bioavailability of trans-resveratrol from red wine in humans," Molecular Nutrition and Food Research, vol. 49, no. 5, pp. 495-504, 2005.

[12] D. M. Goldberg, J. Yan, and G. J. Soleas, "Absorption of three wine-related polyphenols in three different matrices by healthy subjects," Clinical Biochemistry, vol. 36, no. 1, pp. 79-87, 2003.

[13] T. Walle, F. Hsieh, M. H. deLegge, J. E. Oatis Jr., and U. K. Walle, "High absorption but very low bioavailability of oral resveratrol in humans," Drug Metabolism \& Disposition, vol. 32, no. 12, pp. 1377-1382, 2004.

[14] T. Walle, "Bioavailability of resveratrol," Annals of the New York Academy of Sciences, vol. 1215, no. 1, pp. 9-15, 2011.
[15] J.-H. Jang and Y.-J. Surh, "Protective effects of resveratrol on hydrogen peroxide-induced apoptosis in rat pheochromocytoma (PC12) cells," Mutation Research, vol. 496, no. 1-2, pp. 181190, 2001.

[16] A. Quincozes-Santos, L. D. Bobermin, A. Latini et al., "Resveratrol protects $\mathrm{C} 6$ astrocyte cell line against hydrogen peroxideinduced oxidative stress through heme oxygenase 1," PLoS ONE, vol. 8, no. 5, Article ID e64372, 2013.

[17] K. A. Waite, M. R. Sinden, and C. Eng, "Phytoestrogen exposure elevates PTEN levels," Human Molecular Genetics, vol. 14, no. 11, pp. 1457-1463, 2005.

[18] Y. Wang, T. Romigh, X. He et al., "Resveratrol regulates the PTEN/AKT pathway through androgen receptor-dependent and -independent mechanisms in prostate cancer cell lines," Human Molecular Genetics, vol. 19, no. 22, pp. 4319-4329, 2010.

[19] K. A. Waite and C. Eng, "Protean PTEN: form and function," American Journal of Human Genetics, vol. 70, no. 4, pp. 829844, 2002.

[20] A. Ortega-Molina, A. Efeyan, E. Lopez-Guadamillas et al., "PTEN positively regulates brown adipose function, energy expenditure, and longevity," Cell Metabolism, vol. 15, no. 3, pp. 382-394, 2012.

[21] C. Borrás, J. Gambini, M. C. Gómez-Cabrera et al., "17 $\beta$-oestradiol up-regulates longevity-related, antioxidant enzyme expression via the ERK1 and ERK2[MAPK]/NFאB cascade," Aging Cell, vol. 4, no. 3, pp. 113-118, 2005.

[22] C. Borrás, J. Gambini, M. C. Gómez-Cabrera et al., "Genistein, a soy isoflavone, up-regulates expression of antioxidant genes: involvement of estrogen receptors, ERK1/2, and $\mathrm{NF} \kappa \mathrm{B}$," The FASEB Journal, vol. 20, no. 12, pp. 2136-2138, 2006.

[23] A. C. Schmid, R. D. Byrne, R. Vilar, and R. Woscholski, "Bisperoxovanadium compounds are potent PTEN inhibitors," FEBS Letters, vol. 566, no. 1-3, pp. 35-38, 2004.

[24] G. Barja, "Kinetic measurement of mitochondrial oxygen radical production," in Methods in Aging Research, B. P. Yu, Ed., pp. 533-548, CRC Press, Boca Raton, Fla, USA, 1998.

[25] S. Rautiainen, L. Wang, J. M. Gaziano, and H. D. Sesso, "Who uses multivitamins? A cross-sectional study in the Physicians' Health Study," European Journal of Nutrition, 2013.

[26] B. D. Gehm, J. M. McAndrews, P.-Y. Chien, and J. L. Jameson, "Resveratrol, a polyphenolic compound found in grapes and wine, is an agonist for the estrogen receptor," Proceedings of the National Academy of Sciences of the United States of America, vol. 94, no. 25, pp. 14138-14143, 1997.

[27] J. Ashby, H. Tinwell, W. Pennie et al., "Partial and weak oestrogenicity of the red wine constituent resveratrol: consideration of its superagonist activity in MCF-7 cells and its suggested cardiovascular protective effects," Journal of Applied Toxicology, vol. 19, no. 1, pp. 39-45, 1999.

[28] R. T. Turner, G. L. Evans, M. Zhang, A. Maran, and J. D. Sibonga, "Is resveratrol an estrogen agonist in growing rats?" Endocrinology, vol. 140, no. 1, pp. 50-54, 1999.

[29] H. Akca, A. Demiray, M. Aslan, I. Acikbas, and O. Tokgun, "Tumour suppressor PTEN enhanced enzyme activity of GPx, SOD and catalase by suppression of PI3K/AKT pathway in nonsmall cell lung cancer cell lines," Journal of Enzyme Inhibition and Medicinal Chemistry, vol. 28, no. 3, pp. 539-544, 2013.

[30] J. Gambini, R. López-Grueso, G. Olaso-González et al., "Resveratrol: distribution, properties and perspectives," Revista Española de Geriatría y Gerontología, vol. 48, no. 2, pp. 79-88, 2013. 


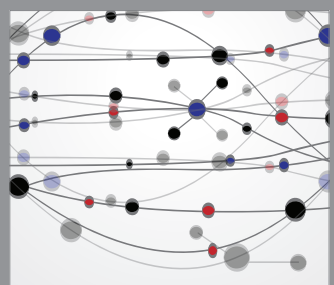

The Scientific World Journal
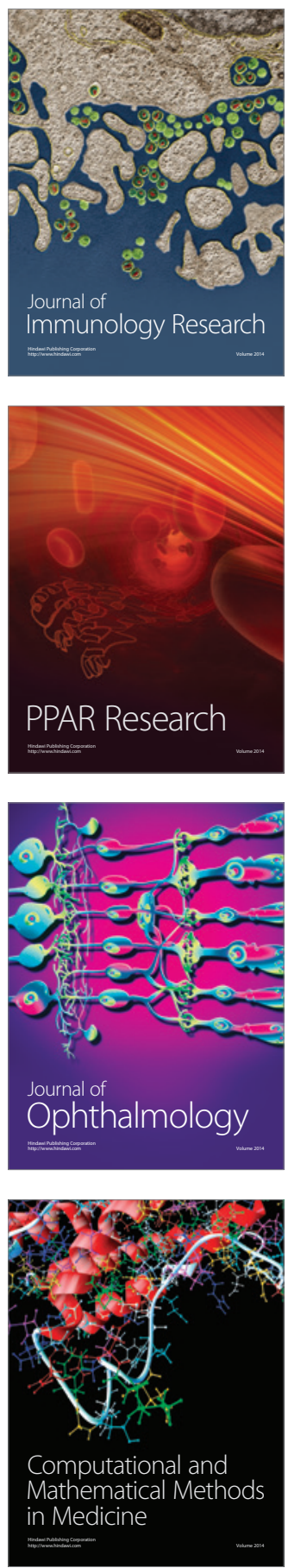

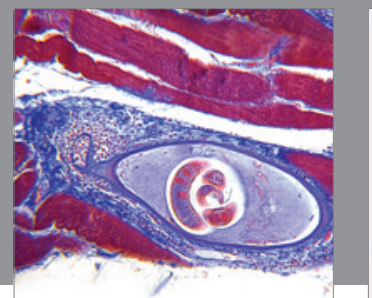

Gastroenterology

Research and Practice
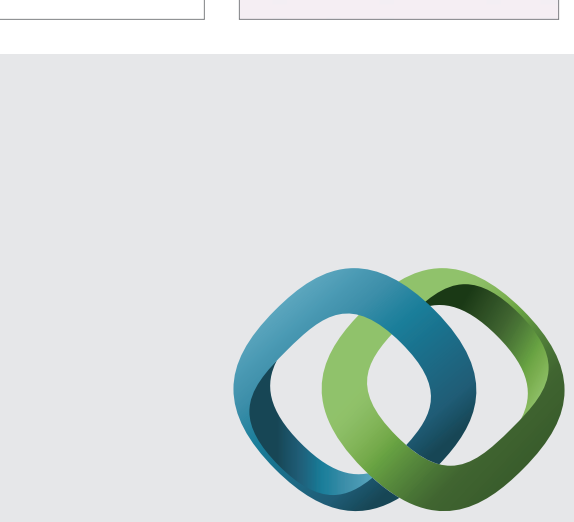

\section{Hindawi}

Submit your manuscripts at

http://www.hindawi.com
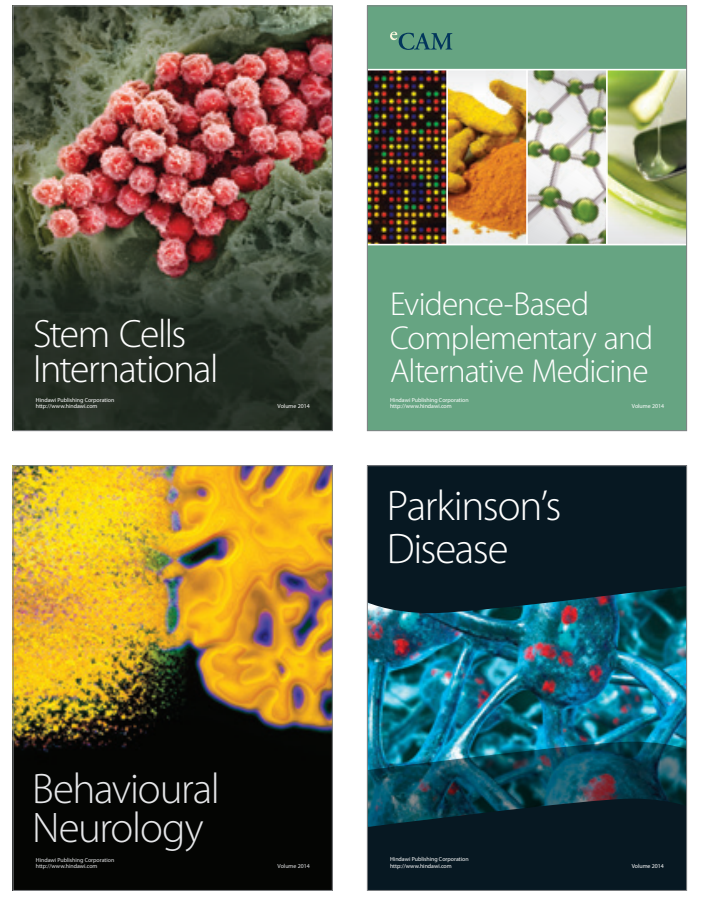
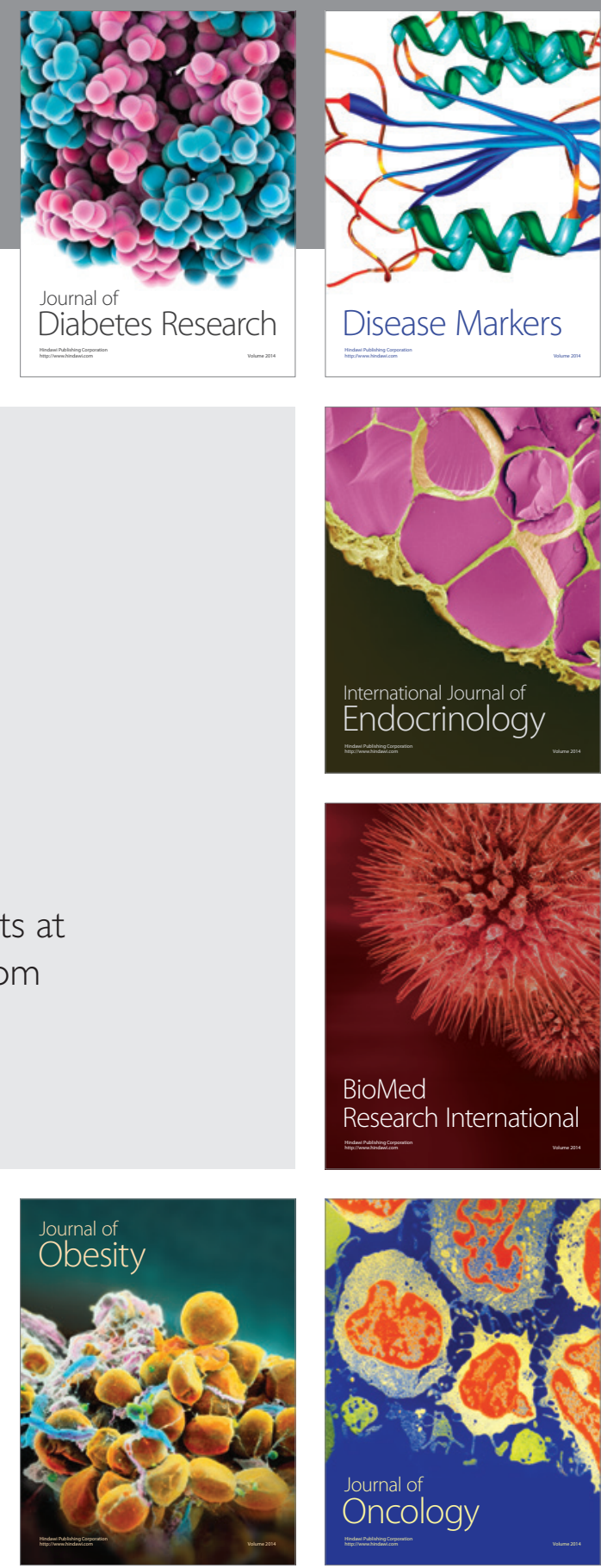

Disease Markers
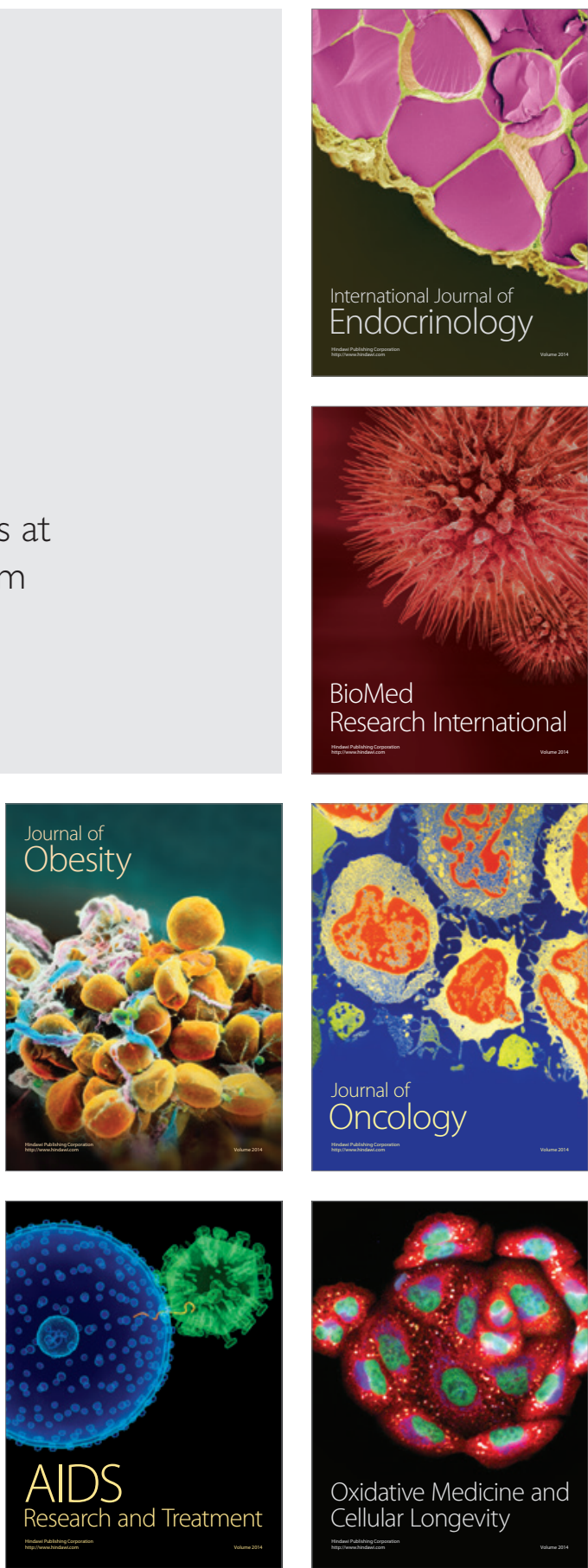